\title{
PODCAST - AN INSIGHT INTO ITS BENEFICENCE IN LANGUAGE LEARNING AND STUDENTS' EXPERIENCE
}

Ivana Jovanović ${ }^{*}$

Academy of Professional Studies

South Serbia - Department for Business

Studies, Leskovac,

Leskovac, Serbia

\section{Correspondence:}

Ivana Jovanović

e-mail:

jovanovic.ivana@vpsle.edu.rs

\begin{abstract}
:
Podcasts and videocasts, well-known Web 2.0 tools have been in use in foreign language teaching for more than a decade now. Extensive research, on a global level, on the potential and proven benefits of using podcasts for developing all language skills (in particular listening), can create a belief that podcasts are now widely used on all levels of foreign language study in Serbia. This type of belief, combined with an ever increasing number of available language learning tools, may lead us to think that in 2021, podcasts are outdated and should be substituted with Web 3.0 or even Web 4.0 tools. However, this paper aims to show that students entering their It $^{\text {st }}$ year of study on a tertiary level are not that familiar with the above mentioned technology and are not informed of their value in both in-class and out-of-class language learning. Bearing in mind the soaring popularity of short digital recordings available online, it is our opinion that the "podcasting culture" is yet to thrive in our country. This will, in turn, lead to an increase in its usage for educational purposes particularly in the field of foreign language teaching and learning.
\end{abstract}

Keywords:

podcasts, language learning, digital technologies, student attitude, educational value.

\section{INTRODUCTION}

Digital technology, particularly Internet based technology has permeated every aspect of our lives and COVID-19 pandemic has greatly contributed to the diffusion of this technology even among those who resist technological change. Amidst the numerous lockdown and quarantine measures imposed on both national and international levels, various types of human activities had to undergo a drastic change, shifting to an online realm. This is certainly true for the educational sector where the World Economic Forum reports an astounding number of 1.2 billion children referred to online learning platforms and tools [1]. In this particular scenario, teachers needed to be as inventive as possible and rely on available, mostly free, resources which could easily and quickly be adapted and efficiently implemented in the teaching process. 
In a Serbian research conducted in 2017, which investigated the methodological application of different digital media in interactive music and language learning, teachers of both English language and music-related subjects stated using podcasts as one of the numerous digital media in their teaching [2]. However, the research did not show how many teachers used podcasts and how frequently.

The availability of such data for the past two (pandemic) years is scarce as well. Furthermore, the applicability of podcasting for teaching and learning English and integration of this technology in the Serbian context should be further researched as there is a lack of available literature in this particular area.

\section{THE EVOLUTION OF EDUCATIONAL TECHNOLOGY}

It has now been more than 15 years since O'Reilly first talked about Web 2.0 (preceded by Arpanet and World Wide Web) and even more since the early days of using technology in classrooms (radio technology in the 1920s, television in the 1950s, programmed learning in the 1960s). Today, in the 21st century we are discussing the use of sensory emotive Web (Web 5.0) where web technology and human interaction become intrinsically intertwined. Authors of [3] as pioneers in the establishment of the theoretical framework for the implementation of podcasting in a university setting particularly stress flexibility, knowledge continuity and learner control as key considerations in deciding on a particular technology in language learning. Podcasting is proven to fill out these criteria besides increasing student contribution in the language learning process and enabling a higher level of cognition (better understanding of the learning materials). While today's podcasts can't be called novel language learning tools, the rise in their popularity over the past few years is shining a new light on them. They are now more than a mode of distributing audio and video content on the Internet.

\section{PODCASTING}

Podcasting technology has first appeared in 2004. and since then has gone through an evolution of its own. Wide adoption of smartphones with internet access led to a prompt rise in the popularity of podcasts. Namely, in 2014, Apple counted 7 billion podcast downloads and in 2018 that number increased to 50 billion podcast downloads and streams [4]. There are currently over 2 million podcast shows and over 48 million episodes on a global level [5]. Podcast.rs (established in 2019 as part of the USAID Strengthening Media System Project) is the most famous Serbian podcasting platform with over 200 available podcasts (both in Serbian and other languages). Currently, there is no available research on the total number of podcasts in Serbia, particularly language learning podcasts prepared and presented by Serbian authors. Still, Spotify, a new music streaming service available in Serbia from 2020 (besides Apple Music and Deezer) and the number of podcasts on Podcast.rs that has doubled in just one year, show a growing interest in this form of technology.

Podcast popularity is said to be related to its numerous advantages such as low production costs, low to medium level of digital literacy needed for their production, affordable price (or no price at all), a wide range of topics to be covered, its transience (so it does not become tiresome and can be "consumed" on the go) and its accessibility to people with visual impairment.

\subsection{DEFINING PODCASTING}

The term podcasting (portable on demand broadcasting) is said to be coined from the terms iPod and broadcasting and it represents a collection of technologies for automatic distribution of audio (and video) content over the Internet through publishing and subscription models [6]. Podcasting is different from the traditional broadcasting as it entails the use of RSS (Really Simple Syndication) technology for the subscription so that the podcast content can be automatically "pushed" to subscribers for download. Users can store their favorite podcasts into online repositories (provided by a particular company offering the very podcasts such as Google, Apple, Podbeam, etc.) or they can download them to their own devices such as laptops, desktop computers, mobile phones, etc.). [7] similarly defines podcasting as the process of capturing an audio event, song, speech, or mix of sounds and then posting that digital sound object to a web site or blog in a data structure called an RSS 2.0 envelope or feed. Podcasts can be categorized based on different criteria but one of the basic ones is made on the form in which they appear:

1. audio podcast (the simplest in form as it contains only audio content);

2. enhanced podcast (with both audio and visual elements - pictures, photos, slides, short videos which all serve to provide additional information on a particular topic); 
3. VODcast (video podcast also known as vlog contains both video and audio files).

Podcasts come in a variety of length (which also serves to show their flexibility) but they mostly last from 20 to 60 minutes with an average length of 41 minutes and 31 seconds in 2019 [8]. In 2019, podcasts in the education category lasted an average of 20.40 minutes while the language learning podcasts seemed to be the shortest, lasting around 7.98 minutes [8].

\subsection{PODCASTING PHASES}

The process of setting up a podcast is rather simple as it can be divided into the following steps - production, publication and generating a RSS feed. Once this is done, the user can subscribe to a podcast (through a podcast aggregator) which enables automatic download of the podcasts.

Lastly, the user can reproduce the contents of a podcast as many times as he/she likes. [9] Discusses 11 steps in creating your own podcast:

1. Creating and editing an audio recording;

2. Recording and interview by phone;

3. Setting up listener feedback;

4. Levelating the podcast;

5. Encoding to MP3 format;

6. Adding ID3 tags;

7. Setting up the hosting service;

8. Creating a Feedburner RSS feed;

9. Validating the feed;

10. Submitting the feed to iTunes, Zune \& Blackberry

11. Submitting your feed to all the other podcast directories.

\section{PODCASTING IN EDUCATION}

From the moment they appeared, podcasts immediately found their use in different educational institutions. Today, podcasts are much more than innovative teaching resources and tools for delivering teaching materials. Research has shown that podcasts have positive effects on students' long-term memory, autonomous learning in students, consistency of student experience, student motivation and engagement, learner discussion, use of different instructional approaches, etc. As technology becomes more advanced and both students and teachers acquire new technology-related skills, it becomes easier and pedagogically justifiable to implement them in all forms of formal learning. The author of [10] discusses unconstitutional use (substitute to traditional lectures), supplementary use (provision of summary and additional materials) and creative educational use of podcasts (constructing knowledge). According to authors of [11], educational podcasts can be divided into: teacher-driven, service-driven, marketing-driven and technology-driven.

\subsection{PODCASTS IN LANGUAGE LEARNING}

Modern languages were one of the first areas identified as being "eligible" to benefits of using audio and video resources. One of the first studies (performed in 2006.) to investigate students' perception and use of podcasts for language learning purposes showed a lack of student knowledge on podcasting technology and $64.9 \%$ of interviewed students stated that they have never or rarely downloaded a podcast [12]. Since then, numerous research pointed out the positive effects of podcasts on students' listening and speaking performance [13], [14], vocabulary acquisition [15], [16] and even perception of self-efficiency in learning English as a foreign language [17]. Previous research on students' perception and attitude towards podcasts in language learning is rather positive as students enjoyed the experience and found it beneficial for their language skills [18], [19], etc.

\section{RESEARCH METHODOLOGY AND RESULTS}

Literature related to the use of podcasting technology in Serbian context is rather scarce and does not offer sufficient information on students' experience in relation to language learning with the aid of this technology. This study was conducted to develop a better understanding of students' familiarity with podcasts (general use and language learning use - whether they have experienced supplemental podcasting and creative podcasting) as well as to understand their attitude toward the use of audio materials in language learning activities (in and out of classroom). We were additionally interested in understanding to what extent are students prepared to implement this technology in their everyday practice of language learning. 
The study was conducted with first year students of Academy of Professional Studies South Serbia Department for Business Studies Leskovac, at the very beginning of the first semester of their study. 37 students agreed to fill out an online questionnaire comprised of 14 questions (close-ended items). The questionnaire was prepared on the basis of a questionnaire used in a research presented in [20], which explored students' readiness and attitudes towards repetitive and supplemental podcasting.

The first three questions obtained information on the accessibility i.e. audio capabilities; the results show that $83,8 \%$ of students currently own a device which can be used to play audio (mp3 files). In terms of listening to audio files, $70,3 \%$ of students said that they mostly use their mobile phones to listen to audio files as opposed to $16,2 \%$ who use their desktop computer and $10,8 \%$ who use their laptop computer to listen to audio files. These results are not surprising since the respondents are digital natives who feel confident in using modern (particularly mobile) technology; question aimed at understanding students' use of mobile technology showed the following:

\begin{tabular}{lccc}
\hline & $\begin{array}{c}\text { Listen } \\
\text { to music }\end{array}$ & $\begin{array}{c}\text { Listen } \\
\text { to audio } \\
\text { books }\end{array}$ & $\begin{array}{c}\text { Listen to } \\
\text { class } \\
\text { lectures, } \\
\text { interviews } \\
\text { (other audio) }\end{array}$ \\
\hline Never & 2 & 25 & 11 \\
\hline Once a month & 3 & 8 & 9 \\
\hline Once a week & 6 & 1 & 8 \\
\hline Once or twice daily & 15 & 2 & 6 \\
\hline Several times daily & 11 & 1 & 3 \\
\hline
\end{tabular}

Table 1 - How frequently do you use a mobile phone for the following activities?

The distribution of answers is quite different in the "listen to music" category as compared to "listen to audio books" and "listen to class lectures, interviews and other audio files". Namely, students $(86,4 \%)$ listen to music on their mobile devices rather often (once a week or more often) while only $10,8 \%$ said to be listening to audio books in the same frequency (once a week or more often). The results are somewhat better for other audio materials as $45,9 \%$ of respondents claim to listen to interviews or any other type of audio materials on a weekly/daily basis.
As for the I year students' familiarity and experience in using podcasting technology, the results indicate a low level of familiarity and experience with podcasts. 51,4\% of students is familiar with the term podcast (as opposed to $48,6 \%$ who are not) and $32,4 \%$ of the respondents said that they have very little knowledge on podcasting technology (a total of $64,8 \%$ without any podcasting knowledge). In view of these findings, the results to the question "How often do you currently download podcasts" came as no surprise $-70,3 \%$ of the students said that they never download podcasts and only 4 students $(10,8 \%)$ claimed to be downloading podcasts fairly often. Podcast subscription seems to be even a greater issue with I year students as $91,9 \%$ of the research participants said that they have never been subscribed to any podcast. In a different question, students were provided with a short definition of a podcast and asked to answer (in view of what a podcast is) if they have ever listened to any type of podcast: $56,8 \%$ of the students answered that they have never listened to a podcast in their life. Furthermore, $81,1 \%$ of the respondents said that they never heard of Podcast.rs - the most famous podcasting platform in Serbia.

Language learning podcasts are not very popular with the research participants. To be specific, we asked the participants to share their experience in using some of the most popular English language learning podcasts (free time activity):

\begin{tabular}{lccc}
\hline & Yes & No & $\begin{array}{c}\text { First time } \\
\text { hearing } \\
\text { about it }\end{array}$ \\
\hline BBC podcasts & 1 & 19 & 17 \\
\hline 5-minute English & 2 & 20 & 15 \\
\hline English To Go & 2 & 18 & 17 \\
\hline ESL Lab & 0 & 17 & 20 \\
\hline $\begin{array}{l}\text { Business English } \\
\text { Pod }\end{array}$ & 3 & 17 & 17 \\
\hline $\begin{array}{l}\text { English Lane } \\
\text { Podcast } \\
* \text { (Serbian author) }\end{array}$ & 1 & 16 & 20 \\
\hline
\end{tabular}

Table 2 - Have you ever used any of the following language learning podcasts?

The results show that very few students have actually used any of the above stated language learning podcasts as the majority hasn't even heard of them. We asked the students to remember if their high school 
or primary school teacher of English language has ever used any podcast in their language class and $56,8 \%$ of the respondents answered No and $37,8 \%$ answered that they might have been exposed to a podcast in their previous language learning experience but that the teacher never stressed that they were listening to a podcast. We were further interested in learning about the overall student experience with audio materials in the language classroom and asked the students how often their high school language teacher used audio materials in his/her teaching.

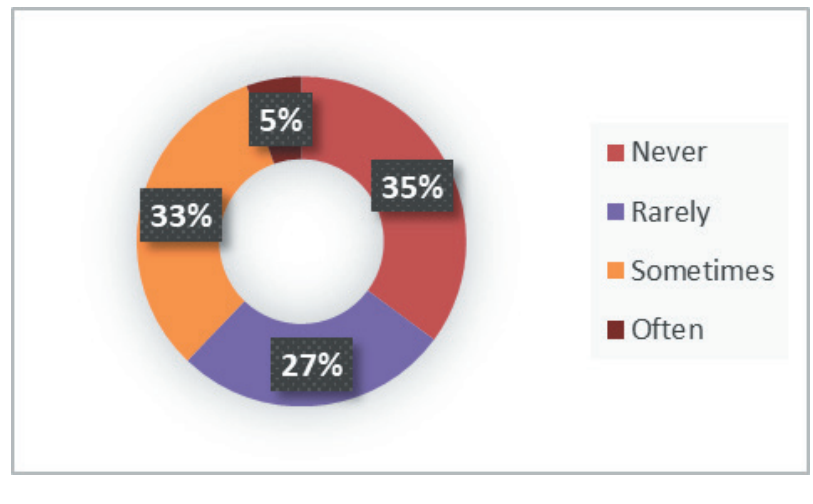

Figure 1 - How often did your high school language teacher use audio materials in the classroom?

None of the students opted for the remaining option named "every class" which stands to show that teachers didn't expose their students to a great deal of listening materials. On the other hand, students who were exposed to audio materials said that they found them beneficial i.e. they believe that audio resources contributed to their learning in that particular class in which they were used (54,1\% gave a positive answer). Finally, we wanted to investigate students' preferences in terms of types of language learning materials and a great majority of students expressed an interest in using both printed and audio materials - 51,4\% (as opposed to using only one of these two types of materials).

While the study was conducted on a small sample, it shows that the first year students aren't familiar with the podcasting technology particularly in terms of its use for foreign language learning. Lack of sufficient exposure to authentic audio materials in their previous foreign language study (formal and informal) hasn't been detrimental to their motivation for using audio tools and language materials which leads us to believe that, with adequate mentoring and progressive integration of podcasting technology, students will be able to comprehend and experience their beneficence in language learning.

\section{IMPLEMENTATION IDEAS AND ACTIVITIES}

Implementation of podcasting technology in a language learning environment depends on numerous factors. The teacher first has to consider the overall course aims and course contents in order to establish a number of learning goals. In line with [21] findings that there are 3 modes of implementing podcasting technology in the language classroom - students as consumers, students as producers and student practice through various exercises, we propose the following ways of implementing podcasts in language learning classrooms:

1. Classroom listening activities (consumers) - listening comprehension quiz, listening comprehension discussion, listen for grammar activities, listen for pronunciation activities, listen for vocabulary activities (jigsaw listening, spot the error, etc.), teacher feedback activities;

2. Classroom speaking and writing activities (producers) - audio and written reviews, audio commentary on social network contents, student interviews (teacher-student interviews, student-guest speaker interviews), audio tours, teleprompter writing/reading/speaking activities, debates, dramatic read-alouds, quick questionand-answer sessions, writing a letter to a podcaster;

3. Practice activities - shadowing activities, practising the pronunciation of a target sound, sentence intonation or rhythm, musical interpretations of provided texts, pair taping free-flow activities.

Teachers should try using both pre-made podcasts (which can be edited to suit particular learning aims) and their own (original) podcasts that can best fit each individual lesson aim and objective.

\section{CONCLUSION}

As technology improves, the importance of having advanced digital skills increases. English language teachers, as many others, are no longer able to rely only on traditional models of teaching and have to look for ways to make language learning more efficient. Audio implementation is a unique way to engage students relatively easy and provide new learning opportunities the students will enjoy and benefit from. Podcasting technology is can be rather easily tied to the already existing teaching methods that some teachers feel more 
comfortable working with. The results of the conducted research show that podcasts are a novelty to students entering tertiary education in the south of Serbia as only a small percentage of students have ever listened to or downloaded a podcast. Research additionally shows a low level of audio exposure in previous language learning together with a positive attitude towards the use of a combination of printed and audio materials in a language classroom.

In view of the proven positive effects of podcasting on student language learning (vocabulary acquisition, development of all four language skills), self-efficiency in language learning, motivation for language learning and other, teachers should first dedicate sufficient time educating themselves on advantages and possibilities of using podcasts as teaching tools. The experience of students involved in the research shows that teachers shy away from using podcasts in their teaching and lack of research in this field in our country adds to the belief that language teachers should pay additional attention to this particular language learning tool. While we may easily assume that all our students are digital natives, teachers should pay special attention to determining the level of technological abilities of their students. Research shows that, when given proper support, students can relatively easily and with little stress involved, overcome the technological hurdle when dealing with the new technology [22]. Teachers should spend an appropriate amount of class time to introduce and explain the medium. Once braving with the new learning tool, teachers need to remain focused on the actual learning outcomes and goals for a particular course and each unit so that the tool fully contributes to their achievement. As podcasting is gaining momentum both in Serbia and globally (particularly in higher education on a global level), further research is needed to understand the full degree of possible hindrances in the implementation of this technology in a local setting. Podcasts, as many other technological advancements, as language learning tools are here to stay - in the words of the author of the famous podcast The House of \#EdTech - the best time to start a podcast was 2004; the next best time is right now [23].

\section{REFERENCES}

[1] Cathy Li and Farah Lalani, "The COVID-19 pandemic has changed education forever. This is how," World Economic Forum, 29 April 2020. [Online]. Available: https://www.weforum.org/agenda/2020/04/coronavirus-education-global-covid19online-digital-learning/. [Accessed 10 May 2021].

[2] S. Marić, Interaktivno učenje muzike i engleskog jezika primenom digitalnih medija, doktorska disertacija, Novi Sad: Univerzitet u Novom Sadu, 2018.

[3] R. M. P. E. a. C. D. Gilly Salmon, "Podcasting technology," in Podcasting for Learning in Universities, Berkshire, Open University Press, 2008, pp. 20-32.

[4] M. Locker, "Apple's podcasts just topped 50 billion all-time downloads and streams," Fast Company, 25 April 2018. [Online]. Available: https://www. fastcompany.com/40563318/apples-podcastsjust-topped-50-billion-all-time-downloads-andstreams. [Accessed 28 April 2021].

[5] R. Winn, „2021 Podcast Stats \& Facts (New Research From Apr 2021), "Podcast Insights, 10 April 2021. [Na mreži]. Available: https://www.podcastinsights.com/podcast-statistics/. [Poslednji pristup 14 May 2021].

[6] C.-T. B. H. \&. Y.-T. T. Chou, "The Critical Factors for Applying Podcast in Mobile Language Learning," in Proceedings of the 2009 International Conference on Information Management and Engineering, Washington, 2009.

[7] P. Meng, "Podcasting \& Vodcasting: A white paper," University of Missouri, Columbia, 2005.

[8] D. Misener, "Podcast episodes got shorter in 2019," Pacific Content, 5 December 2019. [Online]. Available: https://blog.pacific-content.com/podcast-episodes-got-shorter-in-2019-69e1f3b6c82f. [Accessed 2 May 2021].

[9] "Podcast101 - Creating and Hosting an Audio Podcast," podCast411, 10 October 2010. [Online]. Available: http://www.podcast411.com/podcast101/. [Accessed 15 May 2021].

[10] S. Rajic, "Educational use of podcasts," in The Fourth International Conference on e-Learning (eLearning-2013), Belgrade, 2013.

[11] H. H. \&. S. Park, "Educational usages of podcasting," British Journal of Educational Technology, vol. 39, no. 3, pp. 548-551, 2008.

[12] B. O. K. \&. T. M. Monk, "iPods in English language education:A case study of English listening and reading students," NUCB journal of language culture and communication, vol. 8, no. 3, pp. 85-102, 2006. 
[13] N. B. \&. M. R. W. Tryanti Abdulrahman, "The Impact of Podcasts on EFL Students' Listening Comprehension," International Journal of English Linguistics, vol. 8, no. 6, pp. 122-130, 2018.

[14] S. W. C. K. N. C. \&. C. Y. L. Wai Meng Chan, "Students' Perceptions of and Attitudes towards Podcast-Based Learning - A Comparison of Two Language Podcast Projects," Electronic Journal of Foreign Language Teaching, vol. 8, no. 1, pp. 312335, 2011.

[15] H. R. N. S. \&. M. A. Behrooz Ghoorchaei, "Podcasting and Vocabulary Learning in an EFL Context: a Mixed Methods," Research Square, Durham, 2021.

[16] A. H. \&. A. J. Amir Mashhadi, "The Impact of Podcasts on English Vocabulary Development in a Blended Educational Model," Applied Research on English Language, vol. 5, no. 2, pp. 145-172, 2016.

[17] S. B. \&. N. Cabaroglu, "The effect of language learning podcasts on English self-efficiency," Internation Journal of Language Academy, vol. 2, no. 2, pp. 4869, 2014.

[18] G. K. \&. L. Anusienè, "English for Specific Purposes: Podcasts for Listening Skills," Santalka. Filologija. Edukologija, vol. 17, no. 2, pp. 28-37, 2009.

[19] H. C. Li, "Using podcasts for learning English: perceptions of Hong KongSecondary 6 ESL students," ELT World Online, vol. 4, pp. 78-90, 2009.

[20] J. K. J. W. T. A. N. M. D. R. Stephen Walls, "Podcasting in education: Are students as ready and eager as we think they are?," Computer and Education, vol. 54, pp. 371-378, 2010.

[21] T. Robb, "Podcasting for ELT--What, Why and How?," 2006. [Online]. Available: http://www. cc.kyoto-su.ac.jp/ trobb/podcasting2.html. [Accessed 18 April 2021].

[22] B. Philips, "Student-Produced Podcasts in Language Learning - Exploring Student Perceptions of Podcast Activities," IAFOR Journal of Education, vol. 5, no. 3, pp. 157-171, 2017.

[23] C. Nasi, Composer, Audio in Education with Emily Gover. [Sound Recording]. House of \#EdTech . 2016. 